\title{
Molecular profiling of cetuximab and bevacizumab treatment of colorectal tumours reveals perturbations in metabolic and hypoxic response pathways
}

\author{
David W. Greening ${ }^{1, *}$, Sze Ting Lee ${ }^{2,3,4, *}$, Hong $\mathrm{Ji}^{1}$, Richard J. Simpson ${ }^{1}$, Angela \\ Rigopoulos $^{3,4}$, Carmel Murone ${ }^{3,4}$, Catherine Fang ${ }^{3,4}$, Sylvia Gong ${ }^{2}$, Graeme \\ $\mathbf{O}^{\prime} \mathrm{Keefe}^{2,3,4}$ and Andrew M. Scott ${ }^{2,3,4, *}$ \\ ${ }^{1}$ Department of Biochemistry and Genetics, La Trobe Institute for Molecular Science, La Trobe University, Melbourne, Australia \\ ${ }^{2}$ Department of Molecular Imaging and Therapy, University of Melbourne, Austin Hospital, Melbourne, Australia \\ ${ }^{3}$ Tumour Targeting Laboratory, Olivia Newton-John Cancer Research Institute, Melbourne, Australia \\ ${ }^{4}$ School of Cancer Medicine, La Trobe University, Melbourne, Australia \\ * These authors have contributed equally to this work \\ Correspondence to: Andrew M. Scott, email: andrew.scott@onjcri.org.au \\ David W. Greening, email: d.greening@latrobe.edu.au
}

Keywords: cetuximab, bevacizumab, cancer therapeutics, metabolism, hypoxia

Received: August 17, $2015 \quad$ Accepted: September 18, $2015 \quad$ Published: October 26, 2015

This is an open-access article distributed under the terms of the Creative Commons Attribution License, which permits unrestricted use, distribution, and reproduction in any medium, provided the original author and source are credited.

\section{ABSTRACT}

Angiogenesis and epidermal growth factor receptor (EGFR) inhibition has been shown to have anti-tumour efficacy, and enhance the therapeutic effects of cytotoxic chemotherapy in metastatic colorectal cancer. The interplay of signalling alterations and changes in metabolism and hypoxia in tumours following anti-VEGF and antiEGFR treatment is not well understood. We aimed to explore the pharmacodynamics of cetuximab and bevacizumab treatment in human colon carcinoma tumour cells in vitro and xenograft models through proteomic profiling, molecular imaging of metabolism and hypoxia, and evaluation of therapy-induced changes in tumour cells and the tumour microenvironment. Both cetuximab and bevacizumab inhibited tumour growth in vivo, and this effect was associated with selectively perturbed glucose metabolism and reduced hypoxic volumes based on PET/MRI imaging. Global proteomic profiling of xenograft tumours (in presence of cetuximab, bevacizumab, and combination treatments) revealed alterations in proteins involved in glucose, lipid and fatty acid metabolism (e.g., GPD2, ATP5B, STAT3, FASN), as well as hypoxic regulators and vasculogenesis (e.g., ATP5B, THBS1, HSPG2). These findings correlated with western immunoblotting (xenograft lysates) and histological examination by immunohistochemistry. These results define important mechanistic insight into the dynamic changes in metabolic and hypoxic response pathways in colorectal tumours following treatment with cetuximab and bevacizumab, and highlight the ability of these therapies to selectively impact on tumour cells and extracellular microenvironment.

\section{INTRODUCTION}

Colorectal cancer (CRC) is the third most common cancer and the third leading cause of cancer death in men and women worldwide, with nearly 1.4 million new cases diagnosed in 2012 , representing $9.7 \%$ of cancers worldwide [1]. CRC continues to be a significant public issue with $>500,000$ deaths worldwide attributed to this disease annually. About $25 \%$ of patients present with metastatic disease, and of this group, $50-75 \%$ will have the disease confined to the liver [2-5]. Early stage detection significantly improves the clinical outcome [6] 
although this is often made difficult by the lack of specific symptoms [7]. With over $70 \%$ of CRC cases detected at advanced stages, screening remains unsatisfactory and non-specific [8]. Further, in patients who present initially with early-stage disease, up to $50 \%$ will eventually develop metastatic disease.

Significant advances have been made in the treatment of metastatic colorectal cancer (mCRC) [9]. Refinements to cytotoxic chemotherapy regimens have incrementally improved median life expectancy in patients with $\mathrm{mCRC}$, however, such gains have often been attributed with increased toxicity. Recent treatment advances have recognized the role of monoclonal antibodies in the management of $\mathrm{mCRC}$ [10]. International guidelines recommend combination chemotherapy with the addition of a monoclonal antibody (i.e., bevacizumab) for the first-line treatment of $\mathrm{mCRC}$, while for chemoresistant mCRC, cetuximab (erbitux) or panitumumab (vectibix) are recommended as treatment of patients with wild-type $K$-Ras tumours. These targeted agents, now validated in $\mathrm{mCRC}$ and other tumour types, target and perturb critical cell-signalling pathways that regulate (stimulate) tumour angiogenesis and growth.

Bevacizumab disrupts angiogenesis by binding to vascular endothelial growth factor (VEGF)-A, reducing availability of this ligand to its receptors, and preventing their activation. Based on pre-clinical models, bevacizumab has been shown to have both anti-vascular and anti-angiogenic effects, resulting in regression of existing tumour vasculature [11-13], and inhibition of new and recurrent tumour vessel growth $[14,15]$, respectively. This results in a synergistic reduction in tumour size and inhibition in tumour growth. Bevacizumab remains the most important and well-studied drug among the known anti-angiogenic agents. Bevacizumab was the first agent to affect survival in patients with $\mathrm{mCRC}$, improving survival by $30 \%$ [16], with more recent phases II and III clinical trials further demonstrating its significant beneficial effect [17].

Cetuximab, a monoclonal antibody, binds to the extracellular domain of the epidermal growth factor receptor (EGFR), which is overexpressed and active in $\mathrm{mCRC}$. EGFR, a receptor for EGF present on the surface of normal epithelium, is overexpressed in up to $80 \%$ of colorectal tumours $[18,19]$. EGFR mediates cell differentiation, proliferation, migration, angiogenesis and apoptosis, all of which are deregulated in mCRC [20]. Cetuximab directly inhibits tumour growth, induction of apoptosis, inhibition of angiogenesis, inhibition of metastasis, and also exerts anti-angiogenic effects by blocking ligand-induced phosphorylation of EGFR on endothelial cells $[20,21]$. EGF blockade also interferes with VEGF production by tumour cells, suggesting a complementary anti-tumour effect during combination therapies of cetuximab and bevacizumab [22, 23]. Interestingly, tumours with mutations in $K$-Ras are associated with resistance to cetuximab therapy [24, 25]. This underscores the need to identify factors that can predict response or resistance to cetuximab or other such targeted therapies [25].

To explore the pharmacodynamics of bevacizumab and cetuximab treatment, and further our understanding of therapy-induced changes in tumour cells and the tumour microenvironment, we profiled different human-derived CRC xenografts following treatment with these agents alone or in combination. The human CRC cell lines HT-29 and LIM1215 were utilised to investigate responsiveness to bevacizumab/cetuximab monotherapy or combinationbased treatment using human xenograft models. Most significantly, we demonstrate that these targeted therapies had a selective effect on different tumour cells (resistant/weakly responsive), resulting in changes in tumour growth, metabolism, signalling, vasculature, and tissue oxygenation. These findings contribute towards understanding the underlying therapeutic and biological processes associated with monoclonal therapy of EGFR and VEGF anti-tumour activities, and identify further potential protein markers that may contribute in assessment of $\mathrm{mCRC}$ treatment response.

\section{RESULTS AND DISCUSSION}

Cetuximab and bevacizumab are both approved for the treatment of $\mathrm{mCRC}$, however the mechanism of action of both drugs and impact on signalling and metabolic changes in both tumour cells and microenvironment are not fully understood. We therefore explored the effects of treatment of different human CRC models, HT-29 and LIM1215, grown as xenografts with cetuximab and bevacizumab (in addition to combination treatment). To directly monitor and characterise specific anti-tumour activity, molecular imaging of metabolism and hypoxia, proteomic profiling and immunohistochemistry were employed.

\section{Treatment of colorectal xenografts with cetuximab and bevacizumab}

To explore the effects of monotherapy as well as combined therapeutic effect, we subcutaneously injected LIM1215 or HT-29 cells into BALB/c mice, and monitored tumour growth following treatment with control (vehicle, PBS), cetuximab, bevacizumab or cetuximab and bevacizumab combined. Cetuximab and bevacizumab significantly inhibited HT-29 tumour growth compared to control, although the combination of cetuximab and bevacizumab did not provide additional therapeutic benefit (Figure 1A). In LIM1215 tumours, the significant growth inhibition observed with cetuximab and bevacizumab treatment was more pronounced compared to HT-29 tumours, and combination treatment also did not 
demonstrate a significantly improved effect (Figure 1B). These results are consistent with the known differences in response of $\mathrm{mCRC}$ tumours to these therapeutics, and highlight the therapeutic activity of EGFR and VEGF-A antibodies in CRC.

\section{Glucose metabolism and hypoxia following treatment}

To evaluate the in vivo metabolism of tumours following treatment, PET/MRI imaging of mice with HT-29 and LIM1215 tumours at baseline and following treatment was performed with ${ }^{18} \mathrm{~F}-\mathrm{FDG}$ PET, and ${ }^{18}$ F-FMISO PET (Supplementary Figure 1). No difference in glycolytic volumes were found between treated and control HT-29 tumours (Figure 2A), although reduced glycolytic volumes were observed for treated LIM1215 tumours (Figure 2B). Both HT-29 (Figure 2C) and
LIM1215 tumours showed reduced hypoxic volumes following treatment with cetuximab and bevacizumab, more marked in the LIM1215 treated tumours. The reduction in hypoxia reflects the effects of cetuximab and bevacizumab on vasculature through both direct and paracrine effects [25-27].

\section{Immunohistochemistry analysis of tumours}

GLUT-1 expression was reduced following treatment by both bevacizumab and cetuximab, and combination treatment, in both HT-29 and LIM1215 tumours, with cetuximab effect most markedly observed in LIM1215 tumours (Figure 3). HIF-1alpha expression was slightly reduced following treatment with bevacizumab and cetuximab, and combination in HT-29 tumours, however, a greater reduction was observed in LIM1215 tumours (Figure 3), consistent

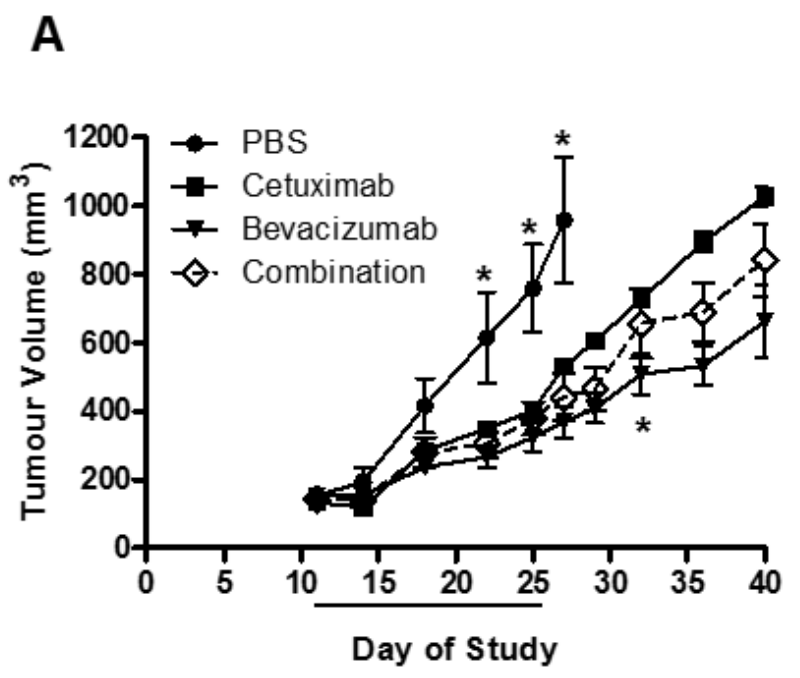

B

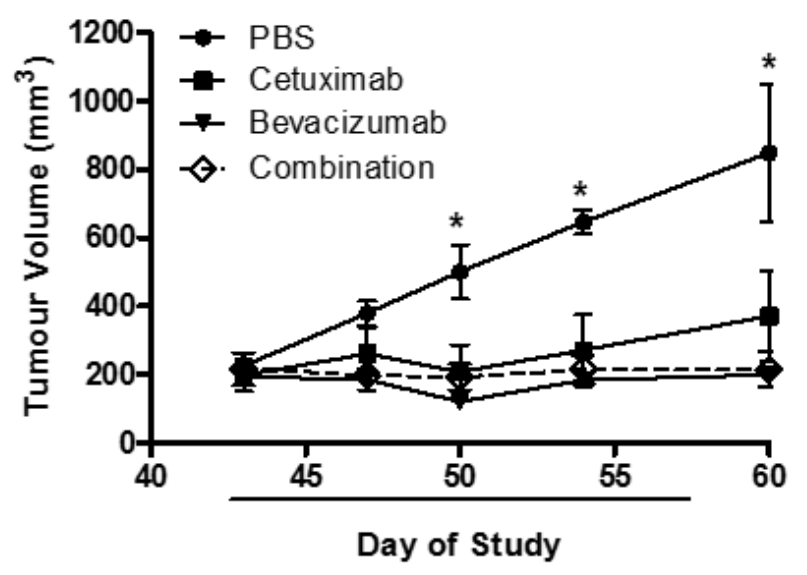

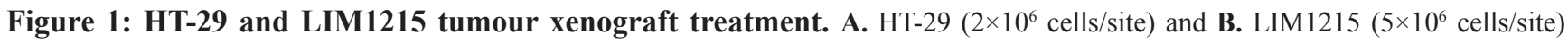
were injected subcutaneously into BALB/c mice inguinal regions. Tumour volumes were measured at indicated times $(n=5$; mean tumour volume $\pm \mathrm{SEM} ;{ }^{*} P<0.05$ ). Treatment cohorts included (1) vehicle (PBS) $2 \mathrm{x} /$ week; (2) cetuximab $-20 \mathrm{mg} / \mathrm{kg} 2 \mathrm{x} / \mathrm{week}$; (3) bevacizumab $-10 \mathrm{mg} / \mathrm{kg} 2 \mathrm{x} /$ week; or (4) the combination treatment both cetuximab $(20 \mathrm{mg} / \mathrm{kg})$ and bevacizumab $(10 \mathrm{mg} / \mathrm{kg}) 2 \mathrm{x} / \mathrm{week}$. 

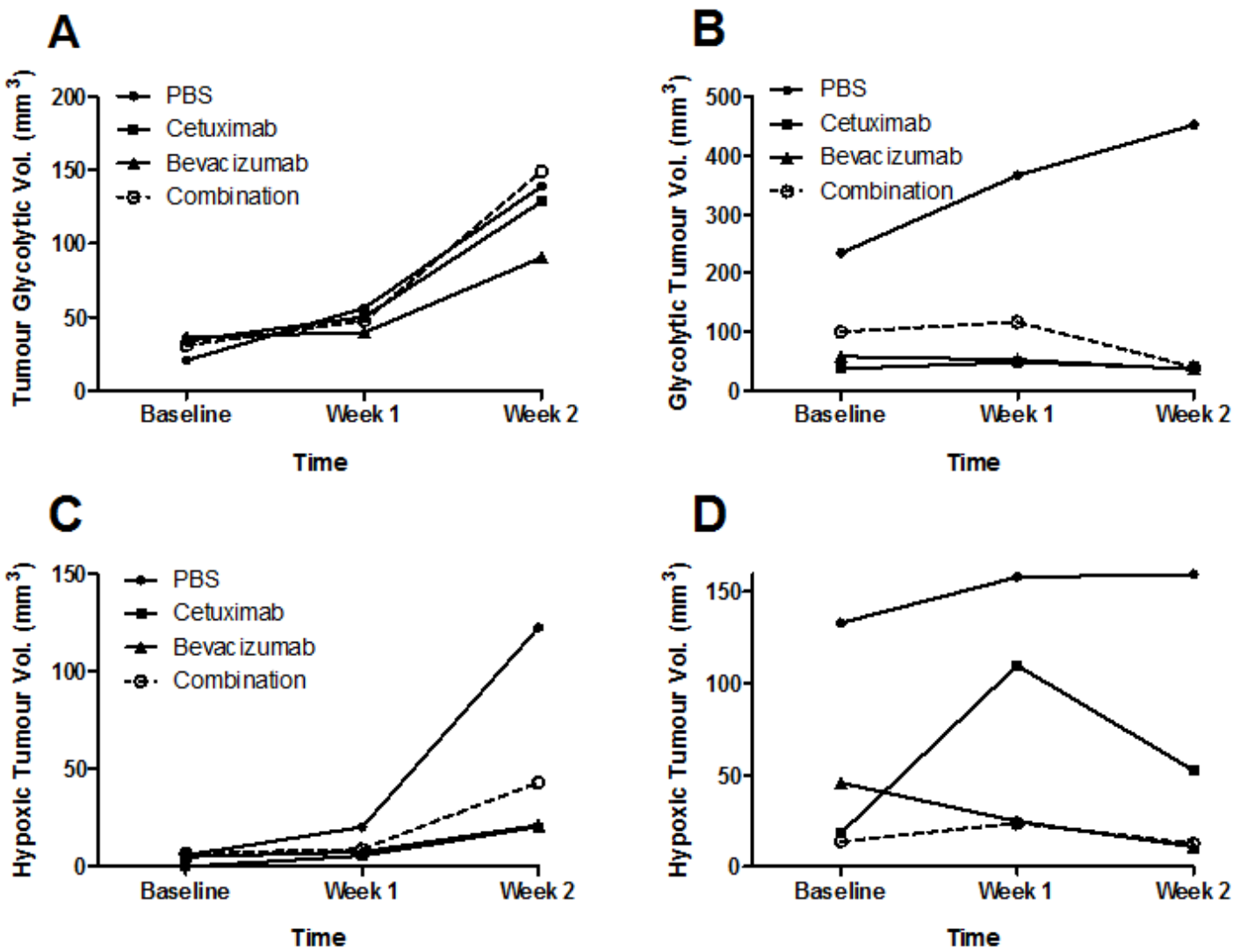

Figure 2: Glycolytic and hypoxic tumour volumes following treatment with cetuximab and bevacizumab. ${ }^{18} \mathrm{~F}-\mathrm{FDG}$ tumour glycolytic volumes of A. HT-29 and B. LIM1215 tumours following treatment with PBS, cetuximab, bevacizumab, or combination. ${ }^{18}$ FMISO PET hypoxic tumour volumes of C. HT-29 and D. LIM1215 tumours following treatment with PBS, cetuximab, bevacizumab, or combination.

HT $-29-C D 31$

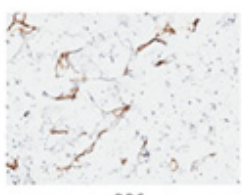

PBS

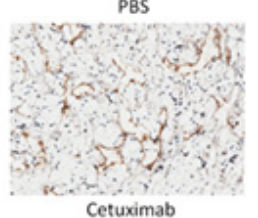

Cetuximab

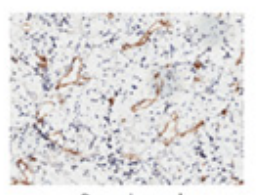

Bevacizumab

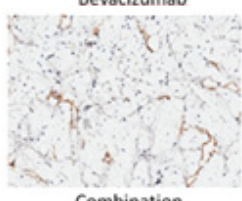

Combination

LIM1215 - CD31

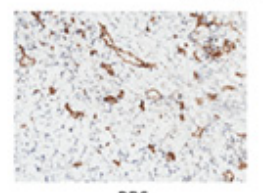

PBS

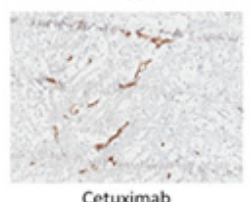

Cetuximab

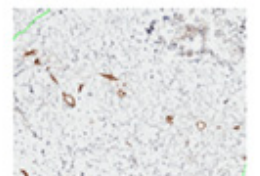

Bevacizumab

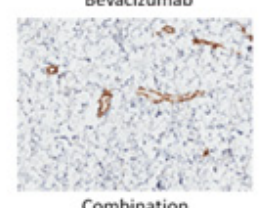

Combination
HT-29 - GLUT1

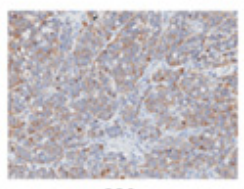

PBS

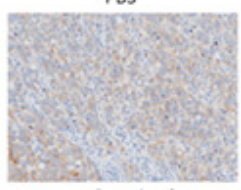

Cetuximab

LIM1215 - GLUT1

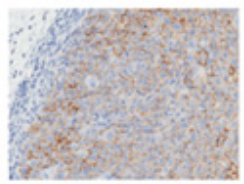

PBS

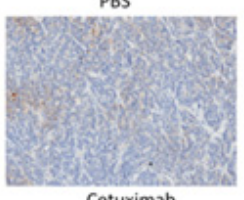

Cetuximab

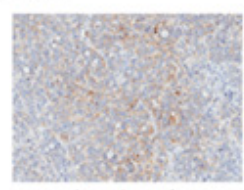

Bevacizumab

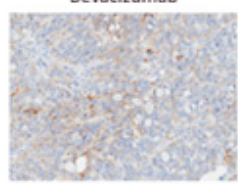

Combination

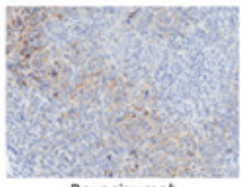

Bevacizumab

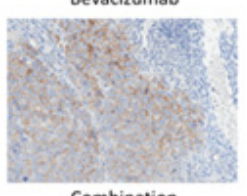

Combination

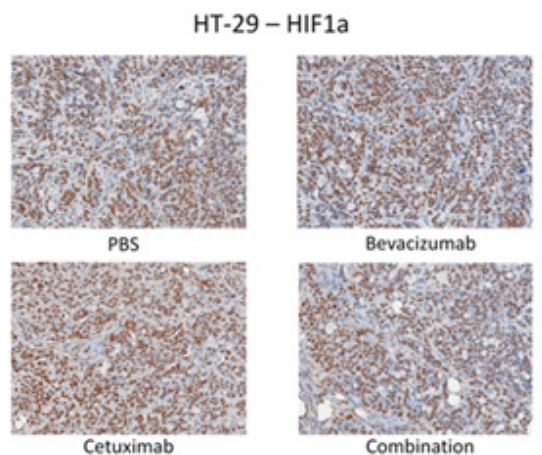

Cetuximab

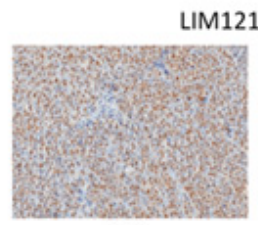

PBS

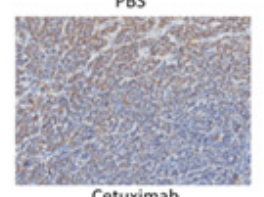

Cetuximab
- HIF1a

Bevacizumab

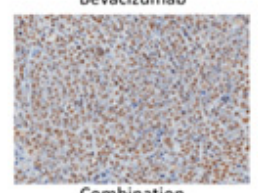

Combination

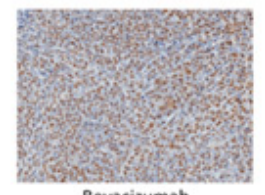

Figure 3: Expression of CD31, GLUT-1 and HIF1-alpha following treatment. Immunohistochemistry results of CD31, GLUT1 and HIF-1alpha in HT-29 and LIM1215 tumours following treatment with PBS, bevacizumab, cetuximab, or combination. 
A

HT-29

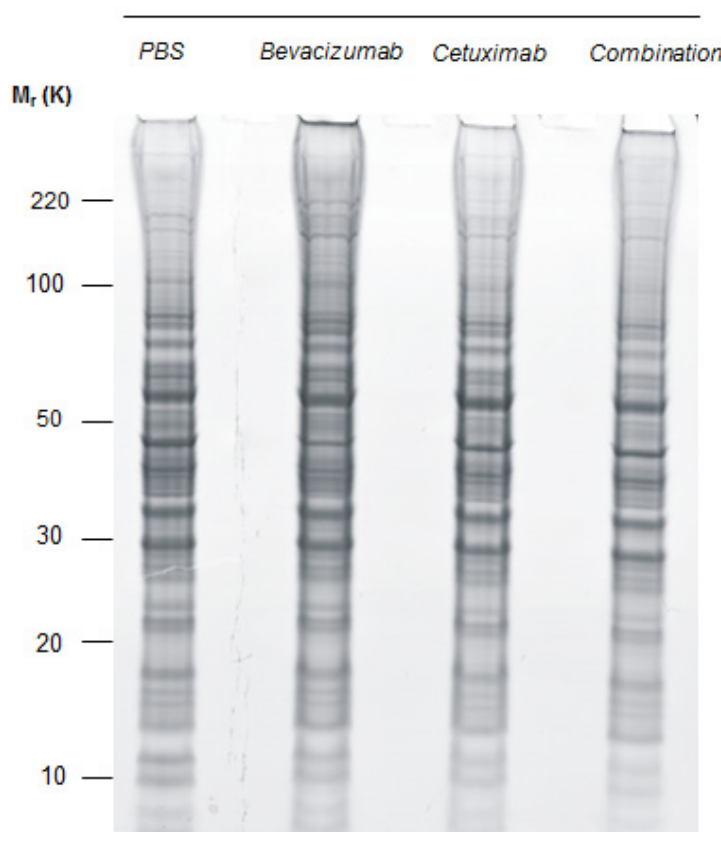

LIM1215
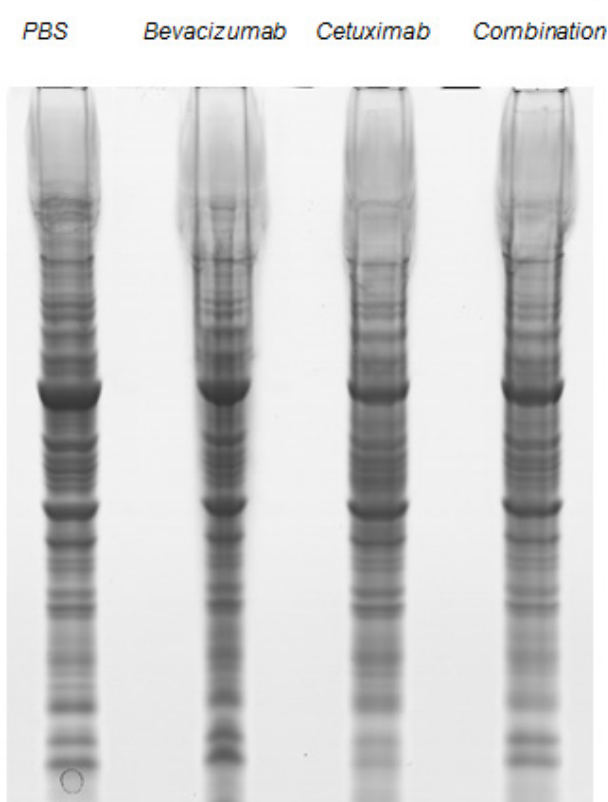

B

Gel slice excision

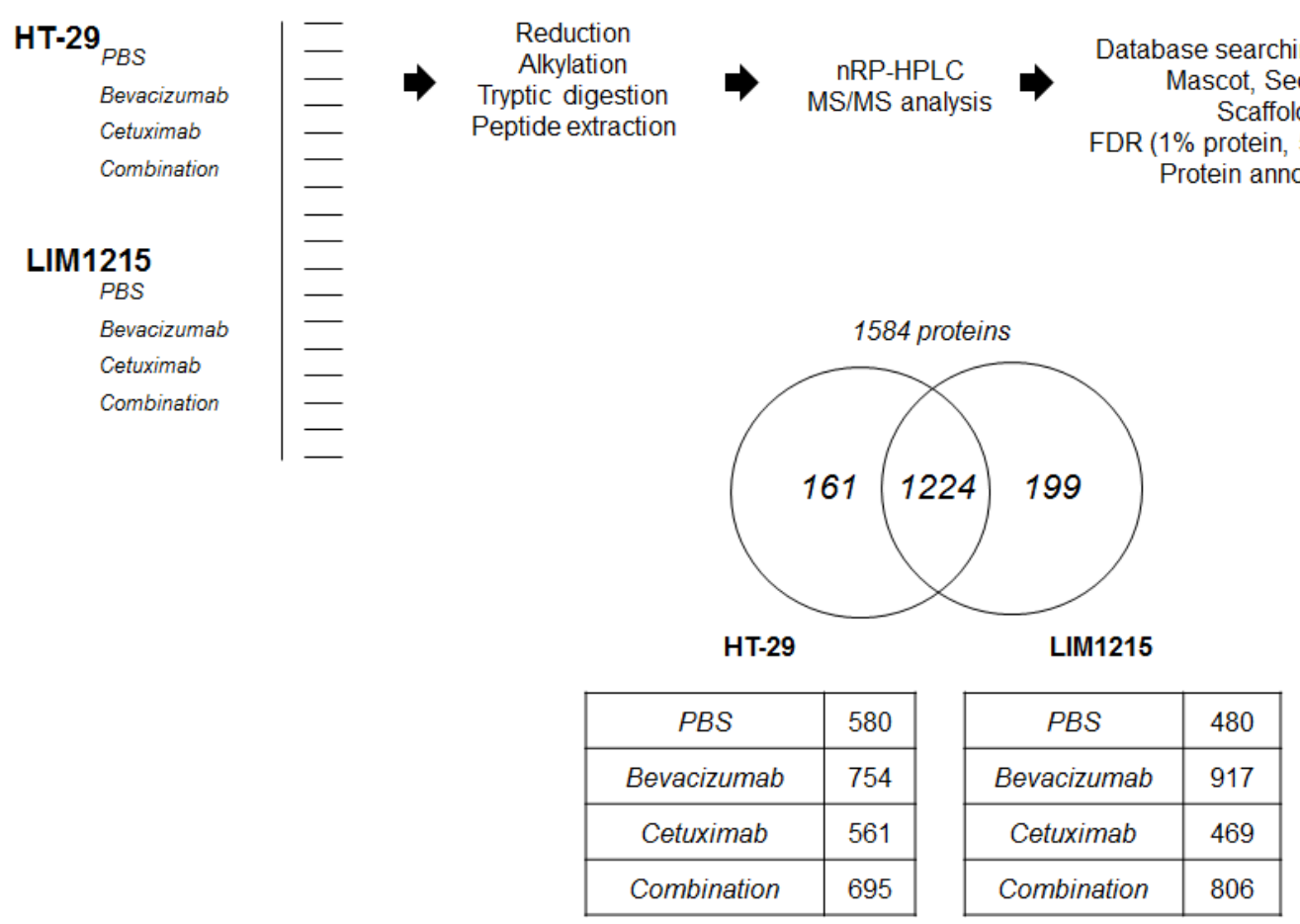

Figure 4: Proteomic characterisation of HT-29 and LIM1215 tumour xenografts in response to cetuximab and/or bevacizumab treatment. A. Proteins extracted from cetuximab and/or bevacizumab treated HT-29 and LIM1215 tumours were separated by 1D-SDS-PAGE and stained with Imperial ${ }^{\mathrm{TM}}$ Protein Stain $(10 \mu \mathrm{g})$. B. Individual gel slices were excised and subjected to in-gel reduction, alkylation, and tryptic digestion. Extracted peptides were separated by nRP-HPLC followed by data-dependent mass spectrometry analysis, database searching, stringent peptide/protein identification, bioinformatic analyses, and protein annotation. A twoway Venn diagram of bevacizumab and cetuximab treated tumour lysates is shown, with 1224 proteins commonly identified between each cell line. The number of identified proteins for control, cetuximab, bevacizumab, and combination treatment cohorts are shown for each tumour-derived xenograft (Supplementary Table S1). 
Table 1: Relative quantification by label-free spectral counting of proteins associated with cellular metabolism

\begin{tabular}{|c|c|c|c|c|c|c|c|c|c|}
\hline \multicolumn{3}{|c|}{ A- Cetuximab } & \multicolumn{3}{|c|}{ HT-29' } & \multicolumn{3}{|c|}{ LIM1215 } & \multirow[b]{2}{*}{ Associated function ${ }^{\mathrm{a}}$} \\
\hline $\begin{array}{c}\text { Protein } \\
\text { Acc }^{\mathrm{a}}\end{array}$ & $\begin{array}{c}\text { Gene } \\
\text { Name }^{\mathrm{a}}\end{array}$ & Protein Description $^{a}$ & $\begin{array}{c}\text { Rsc (PBS v } \\
\text { bevacizumab) }\end{array}$ & $\begin{array}{l}\text { Rsc (PBS v } \\
\text { cetuximab) }\end{array}$ & $\begin{array}{c}\text { Rsc (PBS v } \\
\text { Combination) }\end{array}$ & $\begin{array}{c}\text { Rsc (PBS v } \\
\text { bevacizumab) }\end{array}$ & $\begin{array}{l}\text { Rsc (PBS v } \\
\text { cetuximab) }\end{array}$ & $\begin{array}{c}\text { Rsc (PBS v } \\
\text { Combination) }\end{array}$ & \\
\hline P11216 & PYGB & Glycogen phosphorylase, brain form & -16.5 & 1.2 & -14.2 & -3.8 & -3.5 & -3.5 & $\begin{array}{l}\text { glucose metabolic process; glycogen catabolic process; } \\
\text { glycogen phosphorylase activity }\end{array}$ \\
\hline Q96PK6 & RBM14 & RNA-binding protein 14 & -1.5 & 1.1 & -1.3 & -3.8 & -3.5 & -3.5 & DNA recombination; DNA repair \\
\hline P42704 & LRPPRC & $\begin{array}{l}\text { Leucine-rich PPR motif-containing } \\
\text { protein, mitochondrial }\end{array}$ & -10.6 & 1.1 & -9.1 & -23.8 & -4.3 & -21.7 & $\begin{array}{l}\text { mitochondrion transport along microtubule; mRNA transport; } \\
\text { regulation of transcription }\end{array}$ \\
\hline Q9NYU2 & UGGT1 & $\begin{array}{l}\text { UDP-glucose:glycoprotein } \\
\text { glucosyltransferase } 1\end{array}$ & -4.1 & -1.1 & -3.5 & -5.7 & -5.2 & -5.1 & cellular protein metabolic process; glucosyltransferase activity \\
\hline Q01813 & PFKP & 6-phosphofructokinase type C & -8.6 & -1.2 & -7.4 & -5.7 & -5.2 & -5.1 & glucose metabolic process; glycolytic process \\
\hline Q00341 & HDLBP & Vigilin & -11.3 & -1.6 & -9.7 & -29.3 & -5.3 & -26.7 & cholesterol metabolic process; lipid transport \\
\hline P05023 & ATP1A1 & $\begin{array}{l}\text { Sodium/potassium-transporting } \\
\text { ATPase subunit alpha-1 }\end{array}$ & -15.2 & 2.7 & -13.0 & -10.2 & -9.3 & -9.3 & cellular potassium ion homeostasis \\
\hline Q06210 & GFPT1 & $\begin{array}{l}\text { Glutamine--fructose-6-phosphate } \\
\text { aminotransferase }\end{array}$ & -4.7 & 2.7 & -4.1 & -12.0 & -10.9 & -10.9 & $\begin{array}{c}\text { cellular protein metabolic process; energy reserve metabolic } \\
\text { process } \\
\text { cellular carbohydrate metabolic process; cellular lipid }\end{array}$ \\
\hline P53396 & ACLY & ATP-citrate synthase & -3.4 & -2.2 & -2.9 & -13.8 & -12.6 & -12.6 & $\begin{array}{l}\text { metabolic process; lipid biosynthetic process; positive } \\
\text { regulation of cellular metabolic process } \\
\text { cellular lipid metabolic process; energy reserve metabolic }\end{array}$ \\
\hline P49327 & FASN & Fatty acid synthase & -11.9 & 1.4 & -10.2 & -20.2 & -18.4 & -18.4 & $\begin{array}{c}\text { process; fatty acid biosynthetic process; fatty acid metabolic } \\
\text { process }\end{array}$ \\
\hline P11940 & PABPC1 & Polyadenylate-binding protein 1 & -6.0 & -1.2 & -5.2 & -12.0 & -10.9 & -10.9 & cellular protein metabolic process \\
\hline P11498 & PC & $\begin{array}{l}\text { Pyruvate carboxylase, } \\
\text { mitochondrial }\end{array}$ & -1.5 & -1.7 & -1.3 & -13.8 & -12.6 & -12.6 & $\begin{array}{c}\text { gluconeogenesis; glucose metabolic process; lipid metabolic } \\
\text { process }\end{array}$ \\
\hline \multicolumn{10}{|c|}{ B - Bevacizumab } \\
\hline P40763 & STAT3 & $\begin{array}{l}\text { Signal transducer and activator of } \\
\text { transcription } 3\end{array}$ & 1.2 & 1.1 & 1.4 & -4.8 & -2.4 & -4.3 & cell proliferation; cell differentiation \\
\hline P11413 & G6PD & $\begin{array}{l}\text { Glucose-6-phosphate 1- } \\
\text { dehydrogenase }\end{array}$ & -2.8 & 1.6 & -2.4 & -5.7 & -2.0 & -5.1 & carbohydrate metabolic process; lipid metabolic process \\
\hline P36871 & PGM1 & Phosphoglucomutase-1 & -1.5 & 3.5 & -1.3 & -6.6 & -1.4 & -6.0 & gluconeogenesis; glucose metabolic process \\
\hline Q12906 & ILF3 & $\begin{array}{l}\text { Interleukin enhancer-binding factor } \\
3\end{array}$ & -2.8 & 1.8 & -2.4 & -6.6 & -3.3 & -6.0 & viral defense; transcription \\
\hline P11498 & PC & $\begin{array}{l}\text { Pyruvate carboxylase, } \\
\text { mitochondrial }\end{array}$ & -1.5 & -1.7 & -1.3 & -13.8 & -12.6 & -12.6 & $\begin{array}{c}\text { gluconeogenesis; glucose metabolic process; lipid metabolic } \\
\text { process }\end{array}$ \\
\hline P06576 & ATP5B & ATP synthase subunit beta & -25.7 & -1.7 & -8.5 & 10.7 & 11.5 & 13.3 & $\begin{array}{l}\text { angiogenesis; cellular metabolic process; generation of } \\
\text { precursor metabolites and energy; lipid metabolic process }\end{array}$ \\
\hline P43304 & GPD2 & $\begin{array}{l}\text { Glycerol-3-phosphate } \\
\text { dehydrogenase }\end{array}$ & -2.8 & 1.3 & -2.4 & -16.6 & -1.0 & -15.1 & cellular lipid metabolic process; gluconeogenesis \\
\hline
\end{tabular}

with the hypoxic volume reduction following treatment seen on ${ }^{18}$ F-FMISO PET (Figure 2C and 2D). CD31 expression, a vascular endothelial marker consistent with significant vascularisation, showed minimal change following treatment with bevacizumab or cetuximab in HT-29 tumours, but more marked reduction was seen in LIM1215 tumours (Figure 3), also consistent with the HIF-1alpha results. EGFR expression was reduced following cetuximab treatment in HT-29 and LIM1215 tumours, and VEGF-A showed minimal change following treatment with bevacizumab or cetuximab in either HT29 or LIM1215 tumours (data not shown). These findings correlate with the molecular imaging studies and identify key proteins regulated by cetuximab and bevacizumab treatment.

\section{Proteome analysis of tumour xenograft-derived lysates in response to drug treatments}

To gain insights into the tumour protein expression changes following treatment with bevacizumab and cetuximab we extracted xenograft-derived proteins and performed in-depth proteome profiling using GeLC-MSMS. Protein visualisation using Imperial ${ }^{\mathrm{TM}}$ Protein Stain indicates differences in HT-29 and LIM1215 tumourderived protein profiles in response to bevacizumab and cetuximab, and combination treatments (Figure 4A). GeLC-MS/MS profiling identified a total of 1,584 proteins, comprising 1385 and 1423 in HT-29 and LIM1215, respectively (Figure 4B and Supplementary Table S1). For HT-29 xenograft lysates, we identified 580 (control), 754 (bevacizumab), 561 (cetuximab), and 695 (combination) proteins, while for LIM1215 xenograft lysates we identified 480 (control), 917 (bevacizumab), 469 (cetuximab), and 806 (combination) proteins. To indicate differential protein expression between HT-29 and LIM1215 xenograft samples, and different therapeutic treatments we used normalised relative spectral count ratios (Rsc) to correlate with fold-change [28, 29, 30] and Western immunoblotting.

\section{Anti-tumour effects of cetuximab and bevacizumab mediated through altered cellular metabolism}

In response to cetuximab and bevacizumab, significant changes in tumour xenograft protein expression were observed associated with cellular and glycolytic metabolic processing (Table 1). Most notably, glycerol3-phosphate dehydrogenase (GPD2, Rsc -16.6) and ATP Synthase (ATP5B, Rsc -25.7) (Figure 5) were significantly reduced in expression following bevacizumab treatment in LIM1215 and HT-29, respectively. Further, glucose and glycolytic metabolic-related proteins including STAT3, G6PD PGM1, ILF3, PC, and THBS1 were also 
Table 2: Relative quantification by label-free spectral counting of cetuximab-resistant protein expression

\begin{tabular}{|c|c|c|c|c|c|c|c|c|c|}
\hline \multirow[b]{2}{*}{ Protein Acc ${ }^{a}$} & \multirow[b]{2}{*}{$\begin{array}{c}\text { Gene } \\
\text { Name }^{\mathrm{a}}\end{array}$} & \multirow[b]{2}{*}{ Protein Description ${ }^{a}$} & \multicolumn{3}{|c|}{ HT-29 ${ }^{b}$} & \multicolumn{3}{|c|}{ LIM1215 ${ }^{b}$} & \multirow[b]{2}{*}{ Associated function ${ }^{a}$} \\
\hline & & & $\begin{array}{c}\text { Rsc (PBS v } \\
\text { bevacizumab) }\end{array}$ & $\begin{array}{l}\text { Rsc (PBS v } \\
\text { cetuximab) }\end{array}$ & $\begin{array}{c}\text { Rsc (PBS v } \\
\text { Combination) }\end{array}$ & $\begin{array}{c}\text { Rsc (PBS v } \\
\text { bevacizumab) }\end{array}$ & $\begin{array}{l}\text { Rsc (PBS v } \\
\text { cetuximab) }\end{array}$ & $\begin{array}{c}\text { Rsc (PBS v } \\
\text { Combination) }\end{array}$ & \\
\hline P68371 & TUBB4B & Tubulin beta- $4 \mathrm{~B}$ chain & -2.2 & -1.0 & 1.2 & 48.1 & 28.3 & 52.1 & cytoskeleton remodelling, cytotoxicity \\
\hline P07437 & TUBB & $\begin{array}{l}\text { Tubulin beta chain (Tubulin } \\
\text { beta-5 chain) }\end{array}$ & -2.6 & 1.2 & 1.1 & 31.9 & 16.6 & 36.5 & cytoskeleton remodelling, cytotoxicity \\
\hline P00338 & LDHA & $\begin{array}{l}\text { L-lactate dehydrogenase A } \\
\text { chain }\end{array}$ & 2.7 & 2.8 & 5.0 & 21.1 & 12.2 & 26.7 & Cellular metabolic process, glycolytic process \\
\hline P61204 & ARF3 & ADP-ribosylation factor 3 & 15.0 & 1.1 & 10.6 & 8.0 & 11.9 & 4.9 & Cellular metabolic process, glycolytic process \\
\hline P06576 & ATP5B & $\begin{array}{l}\text { ATP synthase subunit beta, } \\
\text { mitochondrial }\end{array}$ & -25.7 & -1.7 & -8.5 & 10.7 & 11.5 & 13.3 & $\begin{array}{l}\text { Cellular metabolic process, generation of precursor } \\
\text { metabolites and energy }\end{array}$ \\
\hline P62820 & RAB1A & Ras-related protein Rab-1A & 16.0 & 1.1 & 19.9 & 8.7 & 8.8 & 12.7 & Signal transduction \\
\hline P06733 & ENO1 & Alpha-enolase & -3.0 & 1.1 & -2.3 & 20.7 & 7.9 & 22.8 & Glycolytic process \\
\hline P84085 & ARF5 & ADP-ribosylation factor 5 & 11.1 & 1.1 & 8.3 & 6.6 & 7.2 & 5.6 & Signal transduction \\
\hline P18085 & ARF4 & ADP-ribosylation factor 4 & 5.1 & 1.5 & 4.0 & 7.3 & 7.2 & 8.8 & Signal transduction, apoptotic process \\
\hline P31946 & YWHAB & 14-3-3 protein beta/alpha & 34.9 & 1.1 & 33.8 & 30.1 & 5.6 & 29.2 & Apoptotic process \\
\hline P62258 & YWHAE & 14-3-3 protein epsilon & 32.9 & 1.9 & 28.0 & 27.2 & 5.6 & 29.2 & Apoptotic process \\
\hline P27348 & YWHAQ & 14-3-3 protein theta & 22.0 & 1.1 & 28.0 & 25.1 & 5.6 & 25.2 & Apoptotic process \\
\hline P50454 & SERPINH1 & Serpin $\mathrm{H} 1$ & -9.9 & -2.3 & -8.5 & 18.7 & 5.6 & 9.5 & regulation of proteolysis \\
\hline Q9HOU4 & RAB1B & Ras-related protein Rab-1B & 16.0 & 1.1 & 16.4 & 8.0 & 5.6 & 11.1 & Signal transduction \\
\hline 000303 & EIF3F & $\begin{array}{l}\text { Eukaryotic translation } \\
\text { initiation factor } 3 \text { subunit } F\end{array}$ & -4.1 & -2.6 & -3.5 & 6.6 & 5.6 & 8.8 & regulation of translational initiation \\
\hline P31947 & SFN & 14-3-3 protein sigma & 8.2 & -3.2 & 9.9 & 25.8 & 4.9 & 26.8 & Apoptotic process \\
\hline P31943 & HNRNPH1 & $\begin{array}{l}\text { Heterogeneous nuclear } \\
\text { ribonucleoprotein } \mathrm{H}\end{array}$ & -1.3 & -2.2 & 1.4 & 11.5 & 4.9 & 12.7 & regulation of RNA splicing \\
\hline 075390 & CS & $\begin{array}{l}\text { Citrate synthase, } \\
\text { mitochondrial }\end{array}$ & -3.4 & -1.2 & 1.4 & 8.7 & 4.9 & 8.0 & cellular carbohydrate metabolic process \\
\hline P61158 & ACTR3 & Actin-related protein 3 & -5.4 & -1.5 & -4.6 & 7.3 & 4.9 & 7.2 & cytoskeleton remodelling \\
\hline P49327 & FASN & Fatty acid synthase & -11.9 & 1.4 & -10.2 & -20.2 & -18.4 & -18.4 & Cellular metabolic process, lipid metabolism \\
\hline Q08211 & DHX9 & $\begin{array}{l}\text { ATP-dependent RNA helicase } \\
\text { A }\end{array}$ & -5.4 & 1.3 & -4.6 & -16.6 & -15.1 & -15.1 & ATP catabolic process \\
\hline P11940 & PABPC1 & $\begin{array}{l}\text { Polyadenylate-binding } \\
\text { protein } 1\end{array}$ & -6.0 & -1.2 & -5.2 & -12.0 & -10.9 & -10.9 & cellular protein metabolic process \\
\hline P35241 & $\mathrm{RDX}$ & Radixin & -14.5 & 1.0 & -12.5 & -11.1 & -10.1 & -10.1 & cytoskeleton remodelling \\
\hline P07384 & CAPN1 & Calpain-1 catalytic subunit & -4.7 & 1.4 & -4.1 & -8.4 & -7.6 & -7.6 & regulation of cell proliferation \\
\hline P39656 & DDOST & $\begin{array}{l}\text { Dolichyl- } \\
\text { diphosphooligosaccharide-- } \\
\text { protein glycosyltransferase } 48 \\
\text { kDa subunit }\end{array}$ & 1.2 & 1.1 & 3.7 & -1.5 & -6.8 & -6.8 & Cellular metabolic process, glycolytic process \\
\hline Q99613 & EIF3C & $\begin{array}{l}\text { Eukaryotic translation } \\
\text { initiation factor } 3 \text { subunit C }\end{array}$ & 1.2 & 1.1 & 2.6 & -7.5 & -6.8 & -6.8 & cellular protein metabolic process \\
\hline Q14152 & EIF3A & $\begin{array}{l}\text { Eukaryotic translation } \\
\text { initiation factor } 3 \text { subunit A }\end{array}$ & -8.0 & 1.1 & -6.9 & -17.5 & -6.1 & -15.9 & cellular protein metabolic process \\
\hline E7EX73 & EIF4G1 & $\begin{array}{l}\text { Eukaryotic translation } \\
\text { initiation factor } 4 \text { gamma } 1\end{array}$ & -5.4 & -1.1 & -4.6 & -6.6 & -6.0 & -6.0 & cellular protein metabolic process \\
\hline Q9NYU2 & UGGT1 & $\begin{array}{l}\text { UDP-glucose:glycoprotein } \\
\text { glucosyltransferase } 1\end{array}$ & -4.1 & -1.1 & -3.5 & -5.7 & -5.2 & -5.1 & Cellular metabolic process, glycolytic process \\
\hline Q01813 & PFKP & 6-phosphofructokinase type C & -8.6 & -1.2 & -7.4 & -5.7 & -5.2 & -5.1 & Cellular metabolic process, glycolytic process \\
\hline
\end{tabular}

a Protein description, Gene name, UniProt acc, and molecular function annotated from UniProt (http://www.uniprot.org/)

${ }^{\mathrm{b}}$ Normalised spectral count ratio (Rsc) between datasets

significantly reduced in expression following bevacizumab treatment in both LIM1215 and HT-29 tumours.

Citrate synthase (CS, Rsc -1.2) and fatty acid synthase (FASN, Rsc -18.4) were reduced following cetuximab treatment of HT-29 and LIM1215 tumour xenografts, respectively (Table 1). Further, glucose and glycolytic metabolic-related proteins including PYGB, RBM14, LRPPRC, UGGT1, PFKP, HDLBP, ATP1A1, GFPT1, PABPC1, and PC were also significantly reduced in expression following cetuximab treatment in LIM1215 tumours. These findings are consistent with deregulated tumour metabolism (glycolysis, gluconeogenesis, TCA cycle, lipid synthesis) following bevacizumab and cetuximab treatment, particularly in the more responsive LIM1215 treated tumours. This also aligns with the reduced FDG PET uptake (Figure 2A), and immunohistochemistry (Figure 3), and suggests that the metabolic changes are not fully explained by changes in glucose transporter expression.

With regards to alterations in EGFR following cetuximab treatment, several proteins were enriched independently in LIM1215 (and not HT-29) following cetuximab treatment, and were associated with cellular metabolism and signal transduction (Table 2). This selective deregulation is possibly attributed to a reduced response to cetuximab treatment in HT-29 tumours (based on resistance/reduced sensitivity [31]), although some downregulation of total EGFR following treatment was shown (Figure 3). Increased expression of ATP5B (Rsc 10.7), LDHA (Rsc 21.1), CS (Rsc 4.9), the ADPribosylation factors (ARF) 3/4/5 (Rsc 7.2-11.9) (Figure 5) and RAB1A/B (Rsc 5.6-8.8) were observed. Interestingly, ARF4 is known to interact with EGFR and mediate the EGF-dependent signal pathway [32]. ARF4 is a critical molecule that directly regulates cellular PLD2 activity, and that this ARF4-mediated PLD2 activation stimulates AP-1-dependent transcription in the EGF-induced cellular response [33]. Interestingly, this was confirmed using IHC with reduced total EGFR following cetuximab treatment (data not shown). Further upregulated protein classes included cytoskeleton-related proteins (TUBB4B, TUBB, ACTR3), and the protein ENO1 (Rsc 7.9), associated with glycolysis, gluconeogenesis, TCA cycle, and lipid synthesis. This selective deregulation of various metabolic-associated proteins is in agreement with increased anaerobic metabolism as a prominent feature 
Table 3: Angiogenic-associated proteins identified in tumour xenografts in response to anti-tumour treatments

\begin{tabular}{|c|c|c|c|c|c|c|c|c|}
\hline & & & \multirow{2}{*}{\multicolumn{3}{|c|}{ HT-29 ${ }^{\mathrm{b}}$}} & & & \\
\hline & & & & & & \multicolumn{3}{|c|}{ LIM1215 ${ }^{\mathrm{b}}$} \\
\hline $\begin{array}{l}\text { Protein } \\
\text { Acc }^{\mathrm{a}}\end{array}$ & $\begin{array}{l}\text { Gene } \\
\text { Name }^{\text {a }}\end{array}$ & Protein Description $^{\text {a }}$ & $\begin{array}{c}\text { Rsc (PBS v } \\
\text { bevacizumab) }\end{array}$ & $\begin{array}{l}\text { Rsc (PBS v } \\
\text { cetuximab) }\end{array}$ & $\begin{array}{c}\text { Rsc (PBS v } \\
\text { Combination) }\end{array}$ & $\begin{array}{c}\text { Rsc (PBS v } \\
\text { bevacizumab) }\end{array}$ & $\begin{array}{l}\text { Rsc (PBS v } \\
\text { cetuximab) }\end{array}$ & $\begin{array}{c}\text { Rsc (PBS v } \\
\text { Combination) }\end{array}$ \\
\hline P06576 & ATP5B & ATP synthase subunit beta, mitochondrial & -25.7 & -1.7 & -8.5 & 10.7 & 11.5 & 13.3 \\
\hline P06733 & ENO1 & Alpha-enolase & -3.0 & 1.1 & -2.3 & 20.7 & 7.9 & 22.8 \\
\hline Q15582 & TGFBI & $\begin{array}{l}\text { Transforming growth factor-beta-induced protein ig- } \\
\text { h3 }\end{array}$ & -1.5 & 1.1 & -1.3 & -1.1 & 4.9 & -1.0 \\
\hline P42224 & STAT1 & $\begin{array}{l}\text { Signal transducer and activator of transcription 1- } \\
\text { alpha/beta }\end{array}$ & 1.2 & 1.1 & 1.4 & -2.0 & 4.0 & -1.9 \\
\hline P15144 & ANPEP & Aminopeptidase N (AP-N) & -9.3 & -1.6 & -8.0 & -1.1 & 3.3 & -1.0 \\
\hline P29350 & PTPN6 & Tyrosine-protein phosphatase non-receptor type 6 & 1.2 & 1.1 & 1.4 & -1.1 & 2.5 & -1.0 \\
\hline P19971 & TYMP & Thymidine phosphorylase & 1.2 & 1.1 & 1.4 & -1.1 & 2.5 & 5.6 \\
\hline P07195 & LDHB & L-lactate dehydrogenase $B$ chain & 3.2 & 2.6 & 3.0 & 12.2 & -1.0 & 11.1 \\
\hline P48735 & IDH2 & Isocitrate dehydrogenase [NADP], mitochondrial & -8.6 & -1.1 & 1.5 & 10.1 & -1.0 & 6.4 \\
\hline P98160 & HSPG2 & $\begin{array}{l}\text { Basement membrane-specific heparan sulfate } \\
\text { proteoglycan core protein }\end{array}$ & 4.2 & 6.2 & 1.4 & -3.8 & -3.5 & -3.5 \\
\hline P07996 & THBS1 & Thrombospondin-1 & 1.2 & 12.2 & 1.4 & -15.6 & -1.7 & -14.2 \\
\hline
\end{tabular}

${ }^{a}$ Protein description, Gene name, UniProt acc, and molecular function annotated from UniProt (http://www.uniprot.org/)

${ }^{\mathrm{b}}$ Normalised spectral count ratio (Rsc) between datasets

observed in a syngenic model of acquired resistance to anti-EGFR therapy in CRC [34].

For proteins down-regulated independently in LIM1215 (and not HT-29) in response to cetuximab treatment, various cellular metabolic-associated and glycolytic-associated proteins were found (Table 2). These included proteins associated with cellular and lipid metabolism (FASN (Rsc -18.4)), cellular protein metabolism (PABPC1 (Rsc -10.9), EIF3A/C (Rsc -6.16.8), EIF4G1 (Rsc -6.0)), and cellular metabolism/ glycolytic processing (DDOST (Rsc -6.8), UGGT1 (Rsc -5.2), PFKP (Rsc -5.2)). Recently, EGFR has been shown to promote glucose metabolism of chondrosarcoma cells through the upregulation of glycolytic enzymes [35]. Interestingly, cisplatin-resistant chondrosarcoma cells showed upregulated glucose metabolism and EGFR signalling pathway. With regards to FASN expression in response to cetuximab, FASN has been linked to acquired docetaxel/trastuzumab/adriamycin resistance in breast cancer or intrinsic gemcitabine and chemoor radiotherapy resistance in pancreatic cancer. FASN expression is significantly upregulated in pancreatic cancer [36] and inhibition of FASN by siRNA or the FAS inhibitor orlistat reduces gemcitabine resistance, whereas ectopic overexpression of FASN contributes to intrinsic resistance to gemcitabine and radiation $[37,38]$. FASNinduced radiation resistance may result from decrease in radiation-mediated ceramide production, leading to reduced caspase 8-induced apoptosis. However, the mechanism of FASN-induced gemcitabine resistance remains to be elucidated [39]. FASN expression in normal adult tissues is generally very low or undetectable, and it is significantly upregulated and correlates with poor prognosis in many types of cancer. The metabolic products of the FASN complex are rapidly consumed by actively dividing cells and recent data demonstrates that FASN expression is important for tumour growth and survival, suggesting that FASN is a metabolic oncogene [40].

\section{Anti-tumour effects of cetuximab and bevacizumab mediated through altered angiogenesis and hypoxia}

In agreement with Figure $2 \mathrm{C}$ and 2D, we further identified significant deregulation in comparison to vehicle in protein expression associated with HT-29 and LIM1215 tumour xenograft treatments associated with altered angiogenesis and hypoxia. With respect to angiogenesis (Table 3), we observed upregulation in response to cetuximab and bevacizumab (and combination) of 11 proteins in LIM1215 including ATP5B (Rsc 11.5/10.7), ENO1 (Rsc 7.9/20.7) in both cetuximab and bevacizumab (and combination), TGFBI (Rsc 4.9), STAT1 (Rsc 4.0), ANPEP (Rsc 3.3), PTPN6 (Rsc 2.5), and TYMP (Rsc 2.5) in cetuximab, and LDHB (Rsc 12.2), IDH2 (Rsc 10.1) in bevacizumab. Although we observed only a marginal therapeutic effect with HT-29 in response to cetuximab and bevacizumab, we report that HSPG2 (Rsc 6.2/4.2) was upregulated in response to cetuximab and bevacizumab (Figure 5), and THBS1 (Rsc 12.2) in response to bevacizumab. Interestingly, cetuximab treatment reduced HSPG expression (Rsc -3.8) in LIM1215 (Figure 5), which is involved in angiogenesis and cell-cell interactions. Therefore, the protein expression changes in THBS1 and HSPG align with altered vasculogenesis and cell-cell interactions.

Hypoxia is recognized as an important factor contributing to cancer development and drug resistance [41-43]. With regards to hypoxia associated proteins expression changes (based on increased tumour hypoxia volume associated with HT-29, Figure 2C), we report 
Table 4: Hypoxia-related proteins identified in tumour xenografts in response to anti-tumour treatments

\begin{tabular}{|c|c|c|c|c|c|c|c|c|}
\hline \multirow{2}{*}{\multicolumn{3}{|c|}{ A - HT-29 cetuximab }} & \multirow{2}{*}{\multicolumn{3}{|c|}{ HT-29 ${ }^{\mathrm{b}}$}} & \multirow{2}{*}{\multicolumn{3}{|c|}{ LIM1215 $^{\mathrm{b}}$}} \\
\hline & & & & & & & & \\
\hline $\begin{array}{l}\text { Protein } \\
\text { Acc }^{\mathrm{a}}\end{array}$ & $\begin{array}{l}\text { Gene } \\
\text { Name }^{\text {a }}\end{array}$ & Protein Description $^{\mathrm{a}}$ & $\begin{array}{c}\text { Rsc (PBS v } \\
\text { bevacizumab) }\end{array}$ & $\begin{array}{l}\text { Rsc (PBS v } \\
\text { cetuximab) }\end{array}$ & $\begin{array}{c}\text { Rsc (PBS v } \\
\text { Combination) }\end{array}$ & $\begin{array}{c}\text { Rsc (PBS v } \\
\text { bevacizumab) }\end{array}$ & $\begin{array}{l}\text { Rsc (PBS v } \\
\text { cetuximab) }\end{array}$ & $\begin{array}{c}\text { Rsc (PBS v } \\
\text { Combination) }\end{array}$ \\
\hline P07996 & THBS1 & Thrombospondin-1 & 1.2 & 12.2 & 1.4 & -15.6 & -1.7 & -14.2 \\
\hline Q9UJS0 & SLC25A13 & $\begin{array}{l}\text { Calcium-binding mitochondrial carrier } \\
\text { protein Aralar2 } \\
\text { Glutamine--fructose-6-phosphate }\end{array}$ & -1.5 & 3.0 & -1.3 & -2.0 & -1.9 & -1.9 \\
\hline Q06210 & GFPT1 & aminotransferase & -4.7 & 2.7 & -4.1 & -12.0 & -10.9 & -10.9 \\
\hline P55786 & NPEPPS & Puromycin-sensitive aminopeptidase & -2.1 & 2.4 & -1.8 & -7.5 & -2.0 & -6.8 \\
\hline \multicolumn{9}{|c|}{ B - HT-29 bevacizumab } \\
\hline 000151 & PDLIM1 & PDZ and LIM domain protein 1 & 9.1 & 1.1 & 4.9 & 2.3 & -1.0 & 4.1 \\
\hline P07148 & FABP1 & Fatty acid-binding protein & 7.1 & 1.1 & 8.3 & -1.1 & -1.0 & -1.0 \\
\hline 014818 & PSMA7 & $\begin{array}{l}\text { Proteasome subunit alpha type-7 } \\
\text { Transcription elongation factor B }\end{array}$ & 6.2 & 1.1 & 9.5 & 5.8 & -1.0 & 4.1 \\
\hline Q15370 & TCEB2 & polypeptide 2 & 6.2 & 1.1 & 1.4 & 3.0 & -1.0 & 4.9 \\
\hline $\mathrm{P} 42765$ & ACAA2 & 3-ketoacyl-CoA thiolase, mitochondrial & 5.2 & 1.1 & 2.6 & 7.3 & -1.0 & 7.2 \\
\hline
\end{tabular}

a Protein description, Gene name, UniProt acc, and molecular function annotated from UniProt (http://www.uniprot.org/)

${ }^{\mathrm{b}}$ Normalised spectral count ratio (Rsc) between datasets

THBS1 (Rsc 12.2), SLC25A13 (Rsc 3.0), GFPT1 (Rsc 2.7), and NPEPPS (Rsc 2.4) were selectively upregulated in response to cetuximab (Table 4). It has been shown that hypoxia induced drug resistance occurs in gastric cancer cells, whereby cetuximab enhanced oxaliplatin-induced cytotoxicity and apoptosis in normoxia and caused a reversal of drug resistance in hypoxia [44]. Cetuximab was shown to inhibit HIF-1 $\alpha$ expression via the MAPK/ ERK and PI3K/AKT signalling pathways and functions to overcome drug resistance induced by hypoxia. In response to bevacizumab, PDLIM1 (Rsc 9.1), FABP1 (Rsc 7.1), PSMA7 (Rsc 6.2), TCEB2 (Rsc 6.2), and ACAA2 (Rsc 5.2) were upregulated in HT-29 xenograft tumours (Table 4). These data further support the IHC results (Figure 3) of slightly reduced expression of HIF-1alpha, and reduced hypoxic cell fractions observed on FMISO PET (Figure 2C). These data are in partial agreement with Selvakumaran et al., where bevacizumab-treated HT-29/

\section{LIM1215}

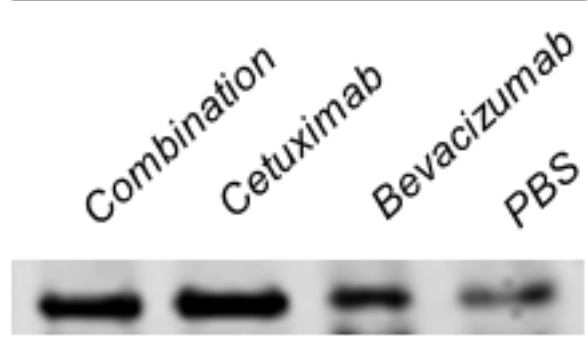

ATP5B

HT29

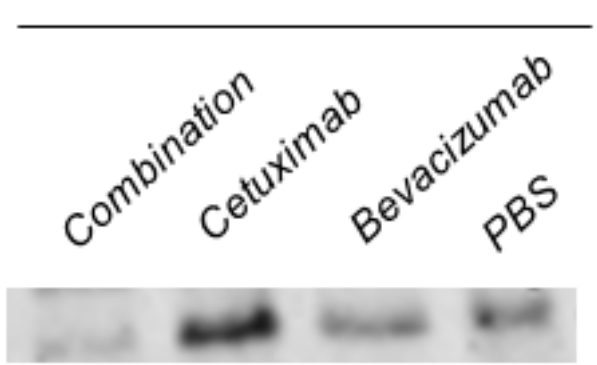

SDC2 (HSPG2)
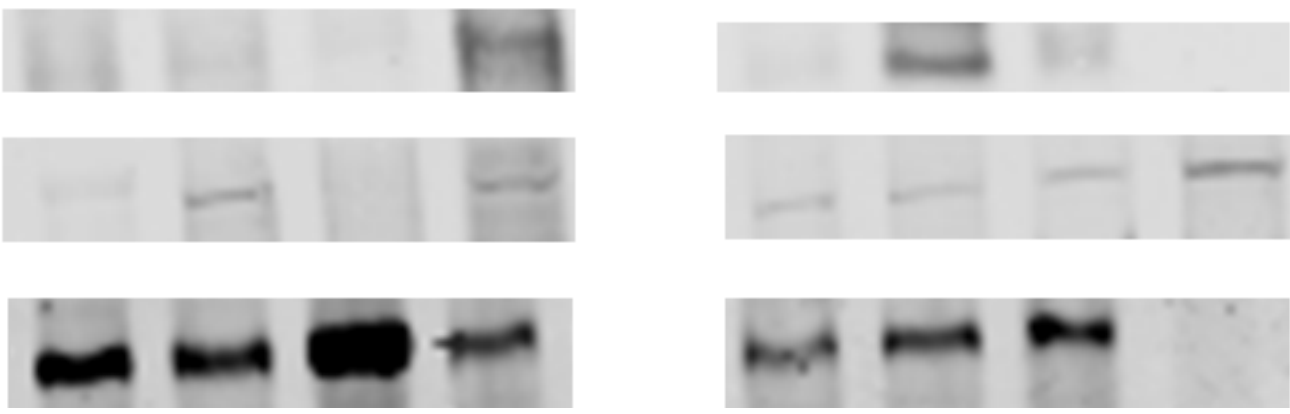
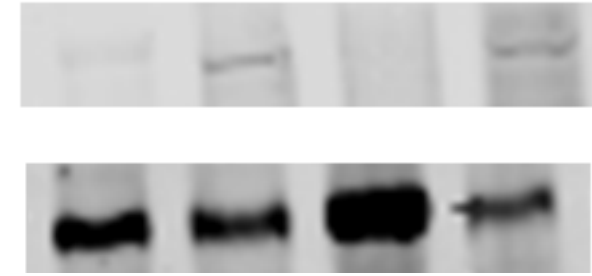

Figure 5: Validation of anti-tumour effects of cetuximab and bevacizumab mediated through altered cellular metabolism. Proteins were extracted from tumour xenografts for each treatment cohort (independent from the tumour xenograft lysates performed for proteomic profiling), obtained from pooled tumour xenograft samples from the validation experimental group $(n=3)$. Immunoblotting analysis of the expression of ATP5B, SDC2, GPD2, ARF4 in both LIM1215 and HT-29 tumour xenograft lysates was performed ( $n=3$; pooled for each treatment cohort, independent biological replicates performed for each antibody). 
HCT116 xenograft tumours showed depletion of tumour microvasculature (i.e., anti-angiogenesis), and increased pimonidazole staining, consistent with an anti-angiogenic effect and induction of hypoxia in tumours [45]. In contrast, we found that HIF-1alpha was downregulated following cetuximab treatment in LIM1215 tumours (Figure 3), although both bevacizumab and cetuximab showed reduced hypoxic fractions on FMISO PET (Figure 2D), and both treatments reduced CD31 expression (Figure 3). These results indicate that cetuximab and bevacizumab also have anti-angiogenic effects which can result in alteration in vascular morphology and reduced hypoxia in tumours.

In summary, our results provide new insights into the interplay of signalling alterations and changes in metabolism and hypoxia response pathways in tumours following inhibition of VEGF and EGFR, and the inhibitory effects on both tumour cells and tumour microenvironment following treatment with cetuximab and bevacizumab. Most significantly, we demonstrate that these targeted therapies were selective on different tumour cells (resistant/weakly responsive), resulting in changes in tumour growth, metabolism, signalling, vasculature, and tissue oxygenation. Future studies which include gene knockdown and overexpression of proteins would provide further evidence of the mechanistic effects of changes in these identified altered proteins. These results identify biologic mechanisms underlying the anti-tumourigenic effects of cetuximab and bevacizumab in CRC, which may lead to a better understanding of the links between metabolism and tumourigenesis in cancer therapy and identifying response markers for anti-tumourigenic therapy.

\section{MATERIALS AND METHODS}

\section{Cell lines}

Human colon carcinoma LIM1215 cells [46] and human colorectal adenocarcinoma HT-29 cells [47] from ATCC were maintained in RPMI-1640 medium, supplemented with $10 \%$ foetal calf serum (RF-10), $10^{-6} \mathrm{M} \alpha$-thioglycerol, $25 \mathrm{U} / \mathrm{L}$ insulin and $1 \mathrm{mg} / \mathrm{mL}$ hydrocortisone.

\section{Xenograft models}

For xenograft and drug treatment assays, $\left(5 \times 10^{6}\right.$ per site) LIM1215 or $\left(2 \times 10^{6}\right.$ per site $)$ HT-29 cells $\left(5 \times 10^{6}\right.$ cells/site) were injected subcutaneously on Day 0 into BALB/c nude mice (Animal Research Centre, Perth, Australia) $(n=5)$ in left flank $[48,49]$. The mice were maintained in microisolater cages housed in a positive pressure containment rack (Thoren Caging Systems Inc.,
Hazelton, PA). Food and water were provided in the cages. The mice were identified by earmarks and weighed twice a week. Tumours were measured twice a week using digital callipers. Tumour volume (TV) was calculated as (length $\mathrm{x}$ width ${ }^{2}$ / 2, where length was the longest axis and width was the perpendicular measurement [50]. Tumour volumes were expressed in $\mathrm{mm}^{3}$, and tumour growth curves were established over time for each cell line. The animals were euthanized when the TV reached $1000 \mathrm{~mm}^{3}$ or if there were any signs of distress prior to this.

\section{Therapy study}

Treatment commenced when mean LIM1215 xenograft TV reached $208 \mathrm{~mm}^{3}$ and mean HT29 xenograft TV was $140 \mathrm{~mm}^{3}$. Groups of 5 mice for each xenograft model were randomly assigned to four treatment cohorts and treated for two weeks with, (1) Vehicle $-100 \mathrm{uL}$ PBS 2x/week; (2) cetuximab - $20 \mathrm{mg} / \mathrm{kg} \mathrm{2x/week;} \mathrm{(3)}$

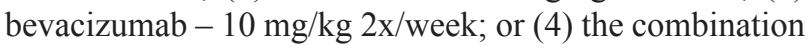
treatment both cetuximab $(20 \mathrm{mg} / \mathrm{kg})$ and bevacizumab (10 mg/kg) 2x/week.

During therapy mice were imaged with ${ }^{18} \mathrm{~F}-\mathrm{FDG}$ and ${ }^{18} \mathrm{~F}$-FMISO on a weekly basis before initial treatment, at commencement (week 0), at week 1 and at week 2 . Tumour volumes were measured twice a week until mice were culled when either tumours reached $>1000 \mathrm{~mm}^{3}$ or if mice were deemed sick based on observation and/or weight loss. One mouse from each cohort was sacrificed when TV reached $200 \mathrm{~mm}^{3}, 500 \mathrm{~mm}^{3}$, and $1000 \mathrm{~mm}^{3}$, after imaging with each PET radiotracer, and correlative measurement of oxygenation was performed. For proteomic profiling and validation studies, tumours ( $n$ =6) from three mice from each treatment cohort after 2 weeks were obtained, and tumours pooled in two separate groups (experimental and validation) and samples stored at $-80{ }^{\circ} \mathrm{C}$.

The animal care and experimentation were performed according to the Australian Code of Practice for the Care and Use of Animals for Scientific Purposes endorsed by the National Health and Medical Research Council. The experimental protocols were approved by our institutional animal ethics committee.

\section{PET/MRI imaging}

For the PET/MRI scans, the animals were anaesthetised in a halothane anaesthetic chamber to minimise background uptake of the radiotracer. The FDG PET scans were performed approximately $60 \mathrm{~min}$ after injection of $0.3 \mathrm{mCi}$ of ${ }^{18} \mathrm{~F}-\mathrm{FDG}$ via a tail vein injection. The FMISO PET scans were performed 120 min after IV injection of $0.5 \mathrm{mCi}$ of ${ }^{18} \mathrm{~F}$-FMISO. Food was withheld from the mice $2 \mathrm{~h}$ prior to FDG injection only, but not for FMISO imaging. The mice were injected with the relevant 
PET radiotracer prior to imaging.

All the PET/MRI imaging was performed on the Mediso nanoScan $\mathrm{PM}^{\circledR}$ (Mediso Medical Imaging Systems, Budapest). The mice were in supine position with the head secured via ear and tooth bars. Respiration was monitored by a pressure-sensitive pad adhered to the abdomen. The MRI scan started with a whole body T1weighted 3D imaging, followed by T2-weighted sequence over the tumour. Following PET list-mode acquisition, the scans were reconstructed using the Tera-TOMO ${ }^{\circledR}$ reconstruction provided by Mediso. Subsequently, reconstructed PET and MR images were transferred to a research PACS system where the images were retrieved for processing by PMOD $^{\circledR}$ for VOI markup.

The mice were sacrificed by over inhalation of isoflurane, and then the tumours were dissected and embedded in Tissue Tek Optimal Cutting Temperature compound (Sakura Finetek, Torrance, CA), frozen in isopentone cooled in liquid nitrogen, and stored at $-80^{\circ} \mathrm{C}$, until further analysis.

\section{PET/MRI image analysis}

The region of interest in each image (ROI) was defined on T2-weighted MRI, and transferred onto all PET images. For FDG PET, the Total Glycolytic Volume (TGV) which is the sum of all glycolytic activity in the tumour was calculated. For FMISO PET, the Total Hypoxic Volume (THV), which is the 3D sum of hypoxic uptake in the tumour, as well as the tumour to Normal Ratio (TNR) of FMISO uptake was also calculated.

\section{Protein extraction and quantification of tumour xenografts}

For each treatment cohort pooled tumour xenograft samples (both experimental and validation) were thawed on ice.. Total protein was harvested from three independent tumour samples in each experimental group (experimental and validation). For protein extraction, lysis buffer $(5 \mathrm{~mL}$ of $(4 \%$ (w/v) SDS, $20 \%$ (v/v) glycerol and $0.01 \%(\mathrm{v} / \mathrm{v})$ bromophenol blue, $0.125 \mathrm{M}$ Tris-HCl, $\mathrm{pH}$ 6.8)) with protease inhibitor cocktail (Complete, EDTAfree protease inhibitor cocktail, Roche) and $1 \mathrm{mM}$ DTT was combined with homogenised tumours and sonicated for $180 \mathrm{~s} \mathrm{[49].} \mathrm{Homogenates} \mathrm{in} \mathrm{each} \mathrm{experimental} \mathrm{group}$ were incubated at $95^{\circ} \mathrm{C}$ for $20 \mathrm{~min}$ and $60^{\circ} \mathrm{C}$ for $2 \mathrm{~h}$. After centrifugation at $25,000 \mathrm{~g}$ for $30 \mathrm{~min}$, each supernatant was subjected to quantification, performed as previously described [29] based on 1D-SDS-PAGE / SYPRO ${ }^{\circledR}$ Ruby protein staining densitometry. This quantification method is reproducible, has a linear quantitation range over three orders of magnitude [51], and is compatible with GeLCMS/MS [29, 52].

\section{Preparation of tumour xenografts for immunohistochemistry}

Four $\mu \mathrm{m}$ sections of the paraffin embedded tissue from different treatment groups were mounted onto SuperFrost ${ }^{\circledR}$ Plus slides (Menzel-Glaser, Braunschweig, Germany), deparaffinized and rehydrated prior to quenching of endogenous peroxidise using $3 \% \mathrm{H}_{2} \mathrm{O}_{2}$ for $10 \mathrm{~min}$. Sections to be stained with GLUT-1 (Thermo Scientific, Waltham, MA, USA) or HIF1-alpha (Abcam, Cambridge, UK) were boiled in a $100{ }^{\circ} \mathrm{C}$ citrate buffer water bath for $30 \mathrm{~min}$ prior to $90 \mathrm{~min}$ ambient temperature incubation with respective primary antibody. For CD31 (BD Pharmingen, San Jose, CA, USA), EGFR (Santa Cruz Biotechnology, Santa Cruz, CA, USA) and VEGF-A (Santa Cruz Biotechnology, Santa Cruz, CA, USA) staining, antibodies were applied to $5 \mu \mathrm{m}$ frozen sections fixed in $4{ }^{\circ} \mathrm{C}$ acetone prior to application of primary antibody. To allow visualization of the immunostaining, sections were incubated with the Envision anti-rabbit-HRP conjugated secondary antibody (Dako, Glostrup, Denmark) and DAB (Sigma, St. Louis MO, USA) and counterstained with Mayer's haematoxylin. Detection of CD31 antibody was done with Vectastain (Vector Laboratories, Burlingame, CA, USA) ABC anti-rat-biotinylated secondary antibody. The histologic appearance of the tissue sections stained for various samples were confirmed with $H \& E$ staining.

Stained sections were scanned using the Aperio (Leica Biosystems, Wetzlar, Germany) Scanscope XT and Aperio image analysis algorithms. For each section, the percentage of positive cells were scored for staining intensity as -, negative; +, weak; ++, moderate; and +++ strong, to give an overall $\mathrm{H}$-score. CD31 was scored as positive pixels in areas of viable tumour and presented as a percentage of viable tumour area.

\section{SDS-PAGE}

Samples were prepared in Lämmli sample buffer (0.06 M Tris-HCl, $2 \%$ (w/v) SDS, $10 \%$ (v/v) glycerol, $0.01 \%$ bromophenol blue, $\mathrm{pH}$ 6.8) containing $50 \mathrm{mM}$ DTT and heated for $5 \mathrm{~min}$ at $95^{\circ} \mathrm{C}$. Proteins were separated on a $4-12 \% \mathrm{NuPAGE}^{\circledR}$ Novex Bis-Tris Gel (Invitrogen) at $150 \mathrm{~V}$ at constant current.

\section{Protein immunoblotting}

For immunoblotting $(10 \mu g)$, proteins were electrotransferred onto nitrocellulose membranes using the iBlot ${ }^{\mathrm{TM}}$ Dry Blotting System (Life Technologies) and membranes blocked with $5 \%(\mathrm{w} / \mathrm{v})$ skim milk powder in Tris-buffered saline with $0.05 \%$ (v/v) Tween-20 (TTBS) for $1 \mathrm{~h}$. Membranes were probed with primary antibodies [mouse anti-ATP5B (Santa Cruz Biotechnology; 1:200), 
mouse anti-GPD2 (Santa Cruz Biotechnology; 1:200), rabbit anti-ARF4 (Abcam; 1:1000), rabbit anti-SDC2/ HSPG2 (OriGene; 1:500)] for $10 \mathrm{~h}$ in TTBS (50 mM Tris, $\mathrm{pH} 7,150 \mathrm{mM} \mathrm{NaCl}, 0.05 \%$ (v/v Tween 20 ) at $4{ }^{\circ} \mathrm{C}$, followed by incubation with either IRDye 800 goat antimouse IgG or IRDye 700 goat anti-rabbit IgG (1:15000, LI-COR Biosciences). Fluorescent signals were detected using the Odyssey Infrared Imaging System, (v3.0, LICOR Biosciences, Nebraska USA).

\section{Proteomic analysis}

Proteomic experiments were performed in duplicate. Tumour xenograft lysates $(20 \mu \mathrm{g})$ were separated using SDS-PAGE and proteins visualized by Imperial ${ }^{\mathrm{TM}}$ Protein Stain (Thermo Fisher Scientific). Each gel lane was cut into 17 individual gel bands (1-2 mm width) and individual gel slices destained (50 $\mathrm{mM}$ ammonium bicarbonate/ acetonitrile), reduced (10 mM DTT (Calbiochem) for 30 $\mathrm{min}$ ), alkylated (50 $\mathrm{mM}$ iodoacetic acid (Fluka) for 30 min) and trypsinized $(0.2 \mu \mathrm{g}$ trypsin (Promega Sequencing Grade) for $16 \mathrm{~h}$ at $37^{\circ} \mathrm{C}$ ), as described [29, 53, 54]. RPHPLC was performed on a nanoAcquity ${ }^{\circledR}$ (C18) $150 \times$ 0.15-mm i.d. reversed phase UPLC column (Waters), using an Agilent 1200 HPLC, coupled online to an LTQ-Orbitrap mass spectrometer equipped with a nanoelectrospray ion source (Thermo Fisher Scientific) [55]. The column was developed with a linear 60 min gradient with a flow rate of $0.8 \mu \mathrm{L} / \mathrm{min}$ at $45^{\circ} \mathrm{C}$ from $0-100 \%$ solvent B where solvent A was $0.1 \%(\mathrm{v} / \mathrm{v})$ aqueous formic acid and solvent B was $0.1 \%(\mathrm{v} / \mathrm{v})$ aqueous formic acid $/ 60 \%$ acetonitrile. The mass spectrometer was operated in data-dependent mode and survey MS scans (300-1500 Th) acquired with the resolution set to a value of 30,000 . Selected precursors were fragmented by CID and real time recalibration performed using a background ion from ambient air in the C-trap [56]. Up to five of selected target ions were dynamically excluded from further analysis for $3 \mathrm{~min}$.

\section{Database searching and protein identification}

Raw data were processed using Proteome Discoverer (v1.4.0.288, Thermo Fischer Scientific) and searched with Mascot (Matrix Science, London, UK; v1.4.0.288), Sequest (Thermo Fisher Scientific, San Jose, CA, v1.4.0.288), and X! Tandem (v2010.12.01.1) against a database of 125,803 ORFs (UniProtHuman, Feb-2015). Data was searched with a parent tolerance of $10 \mathrm{ppm}$, fragment tolerance of $0.6 \mathrm{Da}$, minimum peptide length 6, maximum peptide length 144 , and max delta $\mathrm{CN}$ 0.05 . Peptide lists were generated from a tryptic digestion with up to two missed cleavages, carbamidomethylation of cysteines as fixed modifications, and oxidation of methionines and protein N-terminal acetylation as variable modifications. Peptide spectral matches (PSM) were validated using Percolator based on q-values at a $1 \%$ false discovery rate (FDR) [29, 57]. With Proteome Discoverer, peptide identifications were grouped into proteins according to the law of parsimony and filtered to $1 \%$ FDR [58]. Scaffold (Proteome Software Inc., Portland, OR, v 4.3.4) was employed to validate MS/MS-based peptide and protein identifications from database searching. Initial peptide identifications were accepted if they could be established at greater than $95 \%$ probability as specified by the Peptide Prophet algorithm [58, 59]. Protein identifications were accepted, if they reached greater than $99 \%$ probability and contained at least 2 identified unique peptides. These identification criteria typically established $<1 \%$ false discovery rate based on a decoy database search strategy at the protein level. Proteins that contained similar peptides and could not be differentiated based on MS/MS analysis alone were grouped to satisfy the principles of parsimony. Contaminants, and reverse identification were excluded from further data analysis. UniProt was used to classify identified proteins based on their annotated function, subcellular localisation [60]. The Human Protein Atlas (www.proteinatlas.org) was used as an annotated resource to assess the tissue expression of proteins identified in this study [61].

\section{Semi-quantitative label-free spectral counting}

Significant spectral count normalised (Nsc) and fold change ratios (Rsc) were determined as previously described [28, 29, 52, 54]. The relative abundance of a protein within a sample was estimated using Nsc, where for each individual protein, significant peptide MS/ MS spectra (i.e., ion score greater than identity score) were summated, and normalised by the total number of significant MS/MS spectra identified in the sample. To compare relative protein abundance between samples the ratio of normalised spectral counts (Rsc) was estimated. Total number of spectra was only counted for significant peptides identified (Ion score $\geq$ Homology score). When Rsc is less than 1, the negative inverse value was used. The number of significant assigned spectra for each protein was used to determine whether protein abundances between HT-29 and LIM1215 cells, and different drug treatment categories (control, bevacizumab, cetuximab, combination). For each protein the Fisher's exact test was applied to significant assigned spectra. The resulting p-values were corrected for multiple testing using the Benjamini-Hochberg procedure [62].

\section{Statistical analysis}

Student's $t$-tests (GraphPad v5.0) were calculated, with $* p<0.05$ and $* * p<0.01$ considered statistically significant. 


\section{Abbreviations}

CRC, colorectal cancer

DMEM, Dulbecco's Modified Eagle's Medium

EGFR, epidermal growth factor receptor

FCS, fetal calf serum

mCRC, metastatic colorectal cancer

PET/MRI, positron emission tomography /

magnetic resonance imaging

VEGF, vascular endothelial growth factor

\section{ACKNOWLEDGMENTS}

We acknowledge the Australian Cancer Research Foundation for providing funds to purchase the PET/MRI imaging equipment, and the Victorian Cancer Biobank for access to the Aperio ScanScope XT and analysis algorithms.

\section{FUNDING}

The authors were supported, in part, by the National Health and Medical Research Council (NHMRC) of Australia project grants 1087850 (A.M.S), NHMRC Program Grant 487922 (A.M.S, R.J.S), and a La Trobe University Leadership RFA Grant (D.W.G). This work was also supported by Operational Infrastructure Support Program funding provided by the Victorian Government.

\section{CONFLICT OF INTEREST}

The authors declare no conflict of interest.

\section{REFERENCES}

1. Ferlay J, Soerjomataram I, Dikshit R, Eser S, Mathers C, Rebelo M, Parkin DM, Forman D, Bray F. Cancer incidence and mortality worldwide: sources, methods and major patterns in GLOBOCAN 2012. Int J Cancer. 2015: 136: E359-386.

2. Manfredi S, Lepage C, Hatem C, Coatmeur O, Faivre J, Bouvier AM. Epidemiology and management of liver metastases from colorectal cancer. Ann Surg. 2006: 244: 254-259

3. Goldberg RM. Therapy for metastatic colorectal cancer. Oncologist. 2006: 11: 981-987.

4. Kelly H ,Goldberg RM. Systemic therapy for metastatic colorectal cancer: current options, current evidence. J Clin Oncol. 2005: 23: 4553-4560.

5. Van Cutsem E, Cervantes A, Nordlinger B, Arnold D, Group EGW. Metastatic colorectal cancer: ESMO Clinical Practice Guidelines for diagnosis, treatment and follow-up. Ann Oncol. 2014: 25 Suppl 3: iii1-9.

6. Wong Kee Song LM ,Wilson BC. Endoscopic detection of early upper GI cancers. Best practice \& research. Clinical gastroenterology. 2005: 19: 833-856.

7. Steele RJ. Modern challenges in colorectal cancer. The surgeon : journal of the Royal Colleges of Surgeons of Edinburgh and Ireland. 2006: 4: 285-291.

8. Habermann JK, Bader FG, Franke C, Zimmermann K, Gemoll T, Fritzsche B, Ried T, Auer G, Bruch HP, Roblick UJ. From the genome to the proteome-biomarkers in colorectal cancer. Langenbeck's archives of surgery / Deutsche Gesellschaft fur Chirurgie. 2008: 393: 93-104.

9. Kemeny NE. Treatment of metastatic colon cancer: "the times they are A-changing”. J Clin Oncol. 2013: 31: 19131916.

10. Edwards MS, Chadda SD, Zhao Z, Barber BL, Sykes DP. A systematic review of treatment guidelines for metastatic colorectal cancer. Colorectal Dis. 2012: 14: e31-47.

11. O’Connor JP, Carano RA, Clamp AR, Ross J, Ho CC, Jackson A, Parker GJ, Rose CJ, Peale FV, Friesenhahn M, Mitchell CL, Watson Y, Roberts C, et al. Quantifying antivascular effects of monoclonal antibodies to vascular endothelial growth factor: insights from imaging. Clin Cancer Res. 2009: 15: 6674-6682.

12. Yuan F, Chen Y, Dellian M, Safabakhsh N, Ferrara N, Jain RK. Time-dependent vascular regression and permeability changes in established human tumor xenografts induced by an anti-vascular endothelial growth factor/vascular permeability factor antibody. Proc Natl Acad Sci U S A. 1996: 93: 14765-14770.

13. Lee CG, Heijn M, di Tomaso E, Griffon-Etienne G, Ancukiewicz M, Koike C, Park KR, Ferrara N, Jain RK, Suit HD ,Boucher Y. Anti-Vascular endothelial growth factor treatment augments tumor radiation response under normoxic or hypoxic conditions. Cancer Res. 2000: 60: 5565-5570.

14. Borgstrom P, Hillan KJ, Sriramarao P, Ferrara N. Complete inhibition of angiogenesis and growth of microtumors by anti-vascular endothelial growth factor neutralizing antibody: novel concepts of angiostatic therapy from intravital videomicroscopy. Cancer Res. 1996: 56: 40324039.

15. Pavlidis ET ,Pavlidis TE. Role of bevacizumab in colorectal cancer growth and its adverse effects: a review. World J Gastroenterol. 2013: 19: 5051-5060.

16. Kramer I ,Lipp HP. Bevacizumab, a humanized antiangiogenic monoclonal antibody for the treatment of colorectal cancer. J Clin Pharm Ther. 2007: 32: 1-14.

17. Keating GM. Bevacizumab: a review of its use in advanced cancer. Drugs. 2014: 74: 1891-1925.

18. Lenz HJ. Anti-EGFR mechanism of action: antitumor effect and underlying cause of adverse events. Oncology (Williston Park). 2006: 20: 5-13.

19. Spano JP, Lagorce C, Atlan D, Milano G, Domont J, Benamouzig R, Attar A, Benichou J, Martin A, Morere JF, Raphael M, Penault-Llorca F, Breau JL, et al. Impact of 
EGFR expression on colorectal cancer patient prognosis and survival. Ann Oncol. 2005: 16: 102-108.

20. Martinelli E, De Palma R, Orditura M, De Vita F, Ciardiello F. Anti-epidermal growth factor receptor monoclonal antibodies in cancer therapy. Clin Exp Immunol. 2009: 158: $1-9$.

21. Blick SK ,Scott LJ. Cetuximab: a review of its use in squamous cell carcinoma of the head and neck and metastatic colorectal cancer. Drugs. 2007: 67: 2585-2607.

22. Zhang W, Azuma M, Lurje G, Gordon MA, Yang D, Pohl A, Ning Y, Bohanes P, Gerger A, Winder T, Hollywood E, Danenberg KD, Saltz L, et al. Molecular predictors of combination targeted therapies (cetuximab, bevacizumab) in irinotecan-refractory colorectal cancer (BOND-2 study). Anticancer Res. 2010: 30: 4209-4217.

23. Saltz LB, Lenz HJ, Kindler HL, Hochster HS, Wadler S, Hoff PM, Kemeny NE, Hollywood EM, Gonen M, Quinones M, Morse M ,Chen HX. Randomized phase II trial of cetuximab, bevacizumab, and irinotecan compared with cetuximab and bevacizumab alone in irinotecanrefractory colorectal cancer: the BOND-2 study. J Clin Oncol. 2007: 25: 4557-4561.

24. Lievre A, Bachet JB, Le Corre D, Boige V, Landi B, Emile JF, Cote JF, Tomasic G, Penna C, Ducreux M, Rougier P, Penault-Llorca $F$,Laurent-Puig P. KRAS mutation status is predictive of response to cetuximab therapy in colorectal cancer. Cancer Res. 2006: 66: 3992-3995.

25. Scott AM, Wolchok JD, Old LJ. Antibody therapy of cancer. Nat Rev Cancer. 2012: 12: 278-287.

26. Bergers $G$,Hanahan D. Modes of resistance to antiangiogenic therapy. Nat Rev Cancer. 2008: 8: 592-603.

27. Tabernero J. The role of VEGF and EGFR inhibition: implications for combining anti-VEGF and anti-EGFR agents. Mol Cancer Res. 2007: 5: 203-220.

28. Ji H, Greening DW, Barnes TW, Lim JW, Tauro BJ, Rai A, Xu R, Adda C, Mathivanan S, Zhao W, Xue Y, Xu T, Zhu HJ, et al. Proteome profiling of exosomes derived from human primary and metastatic colorectal cancer cells reveal differential expression of key metastatic factors and signal transduction components. Proteomics. 2013: 13: 16721686.

29. Tauro BJ, Greening DW, Mathias RA, Mathivanan S, Ji H, Simpson RJ. Two distinct populations of exosomes are released from LIM1863 colon carcinoma cell-derived organoids. Mol. Cell. Proteomics. 2013: 12: 587-598.

30. Xu R, Greening DW, Rai A, Ji H, Simpson RJ. Highlypurified exosomes and shed microvesicles isolated from the human colon cancer cell line LIM1863 by sequential centrifugal ultrafiltration are biochemically and functionally distinct. Methods. 2015; In press.

31. Wild R, Fager K, Flefleh C, Kan D, Inigo I, Castaneda S, Luo FR, Camuso A, McGlinchey K, Rose WC. Cetuximab preclinical antitumor activity (monotherapy and combination based) is not predicted by relative total or activated epidermal growth factor receptor tumor expression levels. Mol Cancer Ther. 2006: 5: 104-113.

32. Kim SW, Hayashi M, Lo JF, Yang Y, Yoo JS, Lee JD. ADP-ribosylation factor 4 small GTPase mediates epidermal growth factor receptor-dependent phospholipase D2 activation. J Biol Chem. 2003: 278: 2661-2668.

33 Kim SW, Hayashi M, Lo JF, Yang Y, Yoo JS, Lee JD. ADP-ribosylation factor 4 small GTPase mediates epidermal growth factor receptor-dependent phospholipase D2 activation. J Biol Chem. 2003: 278: 2661-2668.

34. Monteleone F, Rosa R, Vitale M, D'Ambrosio C, Succoio M, Formisano L, Nappi L, Romano MF, Scaloni A, Tortora G, Bianco R ,Zambrano N. Increased anaerobic metabolism is a distinctive signature in a colorectal cancer cellular model of resistance to antiepidermal growth factor receptor antibody. Proteomics. 2013: 13: 866-877.

35. Song YD, Zhang KF, Liu D, Guo YQ, Wang DY, Cui MY, Li G, Sun YX, Shen JH, Li XG, Zhang L ,Shi FJ. Inhibition of EGFR-induced glucose metabolism sensitizes chondrosarcoma cells to cisplatin. Tumour biology : the J Int Soc Oncodevelopmental Biol Med. 2014: 35: 70177024.

36. Bian Y, Yu Y, Wang S, Li L. Up-regulation of fatty acid synthase induced by EGFR/ERK activation promotes tumor growth in pancreatic cancer. Biochem Biophys Res Commun. 2015: 463: 612-617.

37. Yang Y, Liu H, Li Z, Zhao Z, Yip-Schneider M, Fan Q, Schmidt CM, Chiorean EG, Xie J, Cheng L, Chen JH ,Zhang JT. Role of fatty acid synthase in gemcitabine and radiation resistance of pancreatic cancers. Int $\mathrm{J}$ Biochem Mol Biol. 2011: 2: 89-98.

38. Carvalho MA, Zecchin KG, Seguin F, Bastos DC, Agostini M, Rangel AL, Veiga SS, Raposo HF, Oliveira HC, Loda M, Coletta RD, Graner E. Fatty acid synthase inhibition with Orlistat promotes apoptosis and reduces cell growth and lymph node metastasis in a mouse melanoma model. Int J Cancer. 2008: 123: 2557-2565.

39. Yang Y, Liu H, Li Z, Zhao Z, Yip-Schneider M, Fan Q, Schmidt CM, Chiorean EG, Xie J, Cheng L, Chen JH ,Zhang JT. Role of fatty acid synthase in gemcitabine and radiation resistance of pancreatic cancers. International journal of biochemistry and molecular biology. 2011: 2: 89-98.

40. Flavin R, Peluso S, Nguyen PL, Loda M. Fatty acid synthase as a potential therapeutic target in cancer. Future oncology. 2010: 6: 551-562.

41. Sullivan R, Pare GC, Frederiksen LJ, Semenza GL, Graham $\mathrm{CH}$. Hypoxia-induced resistance to anticancer drugs is associated with decreased senescence and requires hypoxiainducible factor-1 activity. Mol Cancer Ther. 2008: 7: 19611973.

42. Hockel M ,Vaupel P. Tumor hypoxia: definitions and current clinical, biologic, and molecular aspects. J Natl Cancer Inst. 2001: 93: 266-276. 
43. Vaupel P ,Mayer A. The clinical importance of assessing tumor hypoxia: relationship of tumor hypoxia to prognosis and therapeutic opportunities. Antioxid Redox Signal. 2015: 22: $878-880$.

44. Luo HY, Wei W, Shi YX, Chen XQ, Li YH, Wang F, Qiu MZ, Li FH, Yan SL, Zeng MS, Huang P ,Xu RH. Cetuximab enhances the effect of oxaliplatin on hypoxic gastric cancer cell lines. Oncology reports. 2010: 23: 17351745.

45. Selvakumaran M, Yao KS, Feldman MD, O'Dwyer PJ. Antitumor effect of the angiogenesis inhibitor bevacizumab is dependent on susceptibility of tumors to hypoxia-induced apoptosis. Biochemical pharmacology. 2008: 75: 627-638.

46. Whitehead RH, Macrae FA, St John DJ, Ma J. A colon cancer cell line (LIM1215) derived from a patient with inherited nonpolyposis colorectal cancer. J. Natl. Cancer Inst. 1985: 74: 759-765.

47. Le Bivic A, Hirn M, Reggio H. HT-29 cells are an in vitro model for the generation of cell polarity in epithelia during embryonic differentiation. Proc Natl Acad Sci U S A. 1988: 85: 136-140.

48. Bernhard OK, Greening DW, Barnes TW, Ji H, Simpson RJ. Detection of cadherin-17 in human colon cancer LIM1215 cell secretome and tumour xenograft-derived interstitial fluid and plasma. Biochim Biophys Acta. 2013: 1834: 2372-2379.

49. Gopal SK, Greening DW, Mathias RA, Ji H, Rai A, Chen M, Simpson RJ. YBX1/YB-1 induces partial EMT and tumourigenicity through secretion of angiogenic factors into the extracellular microenvironment Oncotarget. 2015: 6: 13718-30.

50. Clarke K, Lee FT, Brechbiel MW, Smyth FE, Old LJ, Scott AM. In vivo biodistribution of a humanized anti-Lewis $\mathrm{Y}$ monoclonal antibody (hu3S193) in MCF-7 xenografted BALB/c nude mice. Cancer Res. 2000: 60: 4804-4811.

51. Steinberg TH, Lauber WM, Berggren K, Kemper C, Yue $\mathrm{S}$, Patton WF. Fluorescence detection of proteins in sodium dodecyl sulfate-polyacrylamide gels using environmentally benign, nonfixative, saline solution. Electrophoresis. 2000: 21: 497-508.

52. Tauro BJ, Mathias RA, Greening DW, Gopal SK, Ji H, Kapp EA, Coleman BM, Hill AF, Kusebauch U, Hallows JL, Shteynberg D, Moritz RL, Zhu HJ, et al. Oncogenic $\mathrm{H}$-ras reprograms Madin-Darby canine kidney (MDCK) cell-derived exosomal proteins following epithelialmesenchymal transition. Mol. Cell. Proteomics. 2013: 12: 2148-2159.

53. Shevchenko A, Tomas H, Havlis J, Olsen JV, Mann M. In-gel digestion for mass spectrometric characterization of proteins and proteomes. Nat Protoc. 2006: 1: 2856-2860.

54. Tauro BJ, Greening DW, Mathias RA, Ji H, Mathivanan S, Scott AM, Simpson RJ. Comparison of ultracentrifugation, density gradient separation, and immunoaffinity capture methods for isolating human colon cancer cell line
LIM1863-derived exosomes. Methods. 2012: 56: 293-304.

55. Greening DW ,Simpson RJ. A centrifugal ultrafiltration strategy for isolating the low-molecular weight $(<$ or $=$ $25 \mathrm{~K}$ ) component of human plasma proteome. J Proteomics. 2010: 73: 637-648.

56. Olsen JV, de Godoy LM, Li G, Macek B, Mortensen P, Pesch R, Makarov A, Lange O, Horning S, Mann M. Parts per million mass accuracy on an Orbitrap mass spectrometer via lock mass injection into a C-trap. Mol Cell Proteomics. 2005: 4: 2010-2021.

57. Brosch M, Yu L, Hubbard T, Choudhary J. Accurate and sensitive peptide identification with Mascot Percolator. J Proteome Res. 2009: 8: 3176-3181.

58. Nesvizhskii AI ,Aebersold R. Interpretation of shotgun proteomic data: the protein inference problem. Mol Cell Proteomics. 2005: 4: 1419-1440.

59. Keller A, Nesvizhskii AI, Kolker E, Aebersold R. Empirical statistical model to estimate the accuracy of peptide identifications made by MS/MS and database search. Analytical chemistry. 2002: 74: 5383-5392.

60. Apweiler R, Bairoch A, Wu CH, Barker WC, Boeckmann B, Ferro S, Gasteiger E, Huang H, Lopez R, Magrane M, Martin MJ, Natale DA, O'Donovan C, et al. UniProt: the Universal Protein knowledgebase. Nucleic Acids Res. 2004: 32: D115-119.

61. Uhlen M, Bjorling E, Agaton C, Szigyarto CA, Amini B, Andersen E, Andersson AC, Angelidou P, Asplund A, Asplund C, Berglund L, Bergstrom K, Brumer H, et al. A human protein atlas for normal and cancer tissues based on antibody proteomics. Mol. Cell. Proteomics. 2005: 4: 19201932.

62. Benjamino Y,Hochberg F. Controlling the false discovery rate: a practical and powerful approach to multiple testing. J. R. Stat. Soc. Ser. B-Stat. Methodol. 1995: 57: 289-300. 